\title{
A SCIENTIFIC STUDY OF THE PATINA, CORROSION MORPHOLOGY, AND CONSERVATION OF EGYPTIAN BRASS OBJECT
}

\author{
Gharib, A. \\ Lecturer Conservation dept., Faculty of Fine Arts, Minia Univ., Minia, Egypt \\ E-mail: abeerelalafty@yahoo.com
}

\begin{abstract}
This paper presents the way we used non-destructive methods-optical microscopy (OM), scanning electron microscopy (SEM) coupled with energy dispersive $X$-ray analysis (EDX), $x$ ray diffraction (XRD) and Fourier-transform Raman (FT-Raman) microscopy. The Raman spectra of copper were reported using an Nd-YAG laser operating at an excitation wavelength of 1064, 785and532 $\mathrm{nm}$. These analyses were used to understand the corrosive morphological characteristics of the patina, to investigate the corrosion products, analyze the elementary composition of the copper object and to identify the corrosive factors with effects on the alteration processes. This object exhibited at the museum of the faculty of applied arts, Helwan university-Egypt. The results indicated that the object was made of brass alloy, with copper as the main element, beside zinc. Three layers of alteration products with various composition and morphology covered the substrate of the brass alloy. SEM-EDX, XRD analyses and Raman spectroscopy (RS) revealed the elements $C l, S, O, C$, from primary and secondary chemical compounds and from soil micro-structure. This study provides useful information for the conservation of copper object.
\end{abstract}

Keywords: Copper corrosion, Minerals, Patina, Raman spectroscopy (RS), Brass treatment

\section{Introduction}

The deterioration of ancient metals represent the undesired effect, such as those involve in uncontrolled evolution - corrosion - which gradually alters their aspect, shape, nature and resistance, up to the stage which makes impossible their use as historical evidence of human civilizations or even up to complete destruction of the items [1]. The studies performed on copper alloy object, some of which stayed for long periods in different environments indicated a series of transformations, which allow us to easily establish its current state of conservation reached under the influence of exogenous or endogenous factors. The interdisci-plinary researches on copper alloy artifact showed that the corrosion crusts formed during their stay are different, but according to its morphology, there are three general types (thin, medium and thick) characterized by elements specific to physical deterioration (cracks, pits etc.) and chemical alteration (primary and secondary chemical compounds) [2][3]. Patina or thick corrosion crusts formed on copper alloy artifacts, may display complex products structures. The surface compounds are grouped as: primary or noble patina, poor or secondary patina and tertiary, or contamination patina 
[4][5][6]. The Primary patina formed in the first period of use, initially by oxides and sulfurs of copper, then by basic carbonates of copper, out of which only malachite has a protective and aesthetic function [7]. The secondary patina appears in the final period of use, under the influence of environmental factors with high aggressiveness, mainly in the presence of the chloride anion in an acid medium and of carbon dioxide in an alkaline medium, form nantokite $(\mathrm{CuCl})$, then azurite $\left(\mathrm{Cu}_{3}(\mathrm{OH})_{2}\left(\mathrm{CO}_{3}\right)_{2}\right)$, malachite $\left(\mathrm{Cu}_{2}(\mathrm{OH})_{2} \mathrm{CO}_{3}\right)$, atacamite $\left(\mathrm{Cu}_{2} \mathrm{Cl}(\mathrm{OH})_{3}\right)$, paratacamite $\left(\mathrm{Cu}_{2}(\mathrm{OH})_{3} \mathrm{Cl}\right)$ and so on, distributed more or less evenly over the surface [8]. The processes of the two stages culminate in the soil, during the underground stay period, and they cause serious degradation to the metal core and form crevices and pitting holes. In the stay period the tertiary or contamination patina is formed in the form of new structures, continuously consuming the metallic core and which embed by minerals and various organic and inorganic materials from the surrounding

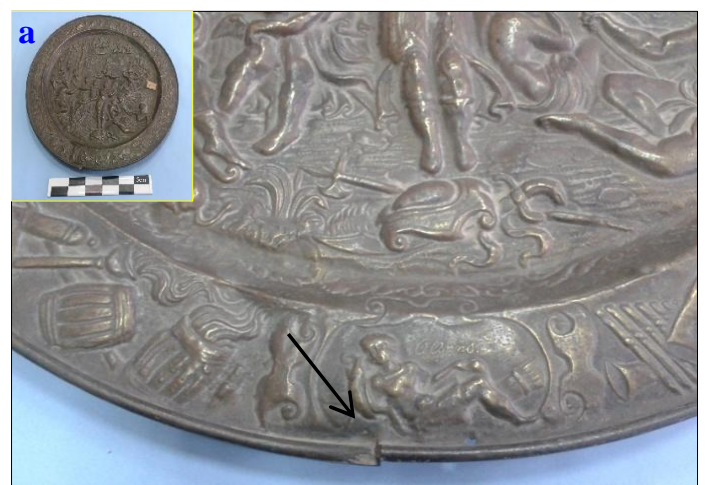

environment in the corrosion crust. In time; organic matter undergoes fossilization processes [9]. The present paper aimed to identify the chemical composition of corrosion layers present on the tray copper object exhibited at the museum of the faculty of applied arts, at Helwan University- Egypt, Cairo; it has no.90/1 and a diameter about $55 \mathrm{Cm}$, it was decorated in multiple levels, and had a lot of deterioration such as a corrosion compounds which covered all the tray and many cracks on the frame and body, fig. (1). Optical Microscopy, scanning electron microscopy (SEM) coupled with energy dispersion $\mathrm{x}$-ray analysis (EDX), $\mathrm{X}$-ray powder diffraction (XRD), and Fourier-transform Raman (FT-Raman) microscopy were used as analytically techniques for both characterizing and identifying the corrosion layers and to investigate the elementary composition of the copper object; to select the appropriate conservation procedures and the degree to which surface cleaning of the copper object that can be carried out.

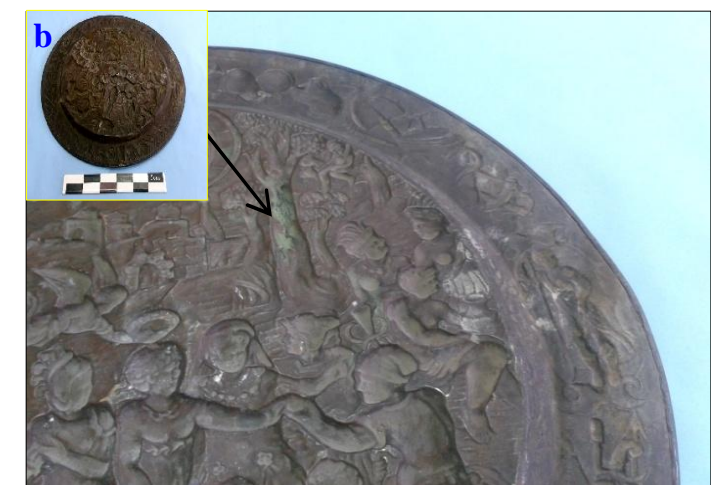

Figure (1) tray copper object from the front and behind shows many corrosion compound, crack and some damage forms.

\section{Materials and Methods \\ 2.1. Optical microscopy}

The optical investigations were carried out using a Smart-Eye USB digital microscope at various magnifycation degrees, up to maximum $200 \mathrm{X}$,

\subsection{Scanning electron microscopy (SEM) coupled with EDX}

Samples investigated by [JEOLJXA840A Electron probe Microscopy], equipped with EDX micro analytical system, SEM allows the observation and surface characterization of materials at a for the investigation of the corrosion products characteristics and the morphology of the corrosion layer.

higher resolution and depth of field that the Conventional optical microscope. In the EDX technique, a solid-state detector is placed close to the sample to emit an electric pulse when the interaction with 
the X-rays is produced. The intensity of the electric pulse is proportional to the energy of the x-ray beam. If the number

\subsection{X-Ray diffraction analysis (XRD)}

Elemental analysis of the surface layer, although very rich in information, does not alone make it possible to identify the components of the patina. For that it is necessary to couple a structure analysis carried out with technique that is non-destructive: $\mathrm{x}$-ray diffraction (XRD); $\mathrm{X}$-ray diffraction identifies the crystalline phases present on the sample on a rather large area $\left(5 \times 2 \mathrm{~mm}^{2}\right)$ [10]. X-ray diffr-

\subsection{Raman spectroscopy}

This paper presents the application of Raman microscopy as a non-destructive technique for the identification of minerals, suitable also for single crystals as small as a few hundred micrometers [11][12][13][14]. The crystals of the copper corrosion minerals were placed and orientated on the stage of a Jasco microscope model (FT/IR-6300 type A), equipped with $10 \mathrm{x}$ and $50 \mathrm{x}$ objectives. Raman microscope system includes a monochromatic, a filter of pulses and the intensity of the x-rays are measured, the chemical composition of the sample can be determined [10].

action analysis carried out with X-ray diffraction equipment model (XPERTPRO-P Analytical), $\mathrm{Cu}$ radiation $1.54056 \mathrm{~A}^{\circ}$ at $45 \mathrm{KV} / 40 \mathrm{~mA}$. With used high resolution graphite monochromatic; rotating sample holder and a proportional detector. Measurements carried out on powders of the samples, in the range $0^{\circ}<$ $2 \theta<70^{\circ}$ with a step of $0.02^{\circ}$.

system $(3000 \mathrm{~Hz})$ and detector. Raman spectra were excited by Nd-YAG laser $1064 \mathrm{~nm}$ at a resolution of $16 \mathrm{Cm}-1$ in the range between 50 and $4000 \mathrm{Cm}-1$ and scanning speed is $(0.5 \mathrm{~mm} / \mathrm{sec})$. A Senterra Raman spectrometer (Bruker) was used also in the current work, equipped with $20 \mathrm{x}$ objective lens; a filter system and a Charge Coupled Device (CCD). Raman spectra excited by NdYAG laser $532 \mathrm{~nm}$ and $785 \mathrm{~nm}$ in the range between 100 and $4000 \mathrm{Cm}-1$.

\section{Results}

\subsection{Optical microscopy}

Optical microscope observation were primarily carried out without any preparation in order to keep the surface intact, Macroscopic observations allowed us to recognize the corrosion deposits and layers that completely covered the surface of the copper object, their color, nature, and shape. The observation micro-photographs show the colors, and the layer morphology of the patina. The substrate has a reddish brown color, some reddish orange lustrous crystals and has some fissures and cavities. The first
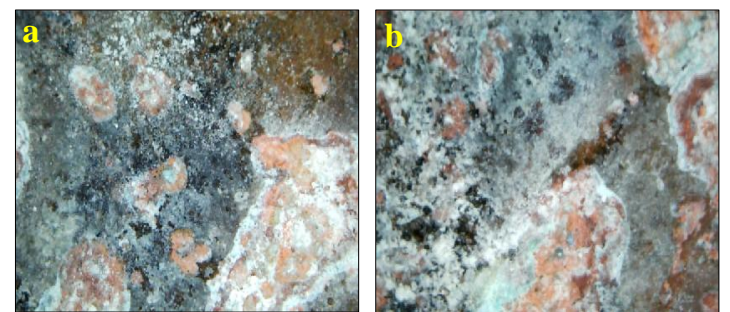

internal layer of patina layers, which in contact with the alloy is irregular in shape and thickness, is sometimes not observed, coherent and has a dark brown to blackish color, concealed beneath an overlying layer of green-blue basic salts, as corrosion products. The later layer is thicker than the previous and is covered with an outer, even thicker layer that has amorphous compounds incorporated with soil crystalline compounds and covers most of the surface, fig. (2).

Figure (2) microscopic images of brass object show the morphology of the corrosion crust- $200-X, \underline{\mathbf{a}}, \underline{\mathbf{b}}$ the first internal layer of patina layers have some reddish orange crystals and some cavities, $\underline{\mathbf{c}}, \underline{\mathbf{d}}$ the green and blue corrosion product. 


\subsection{Scanning electron microscopy (SEM) coupled with EDX}

Sample from copper object were investigated and analyzed with scanning electron microscopy coupled with EDX microanalysis, investigation of the sample showed the metal surface was pitted and etched, fig. (3-a) at magnification 3000x and the depth of the

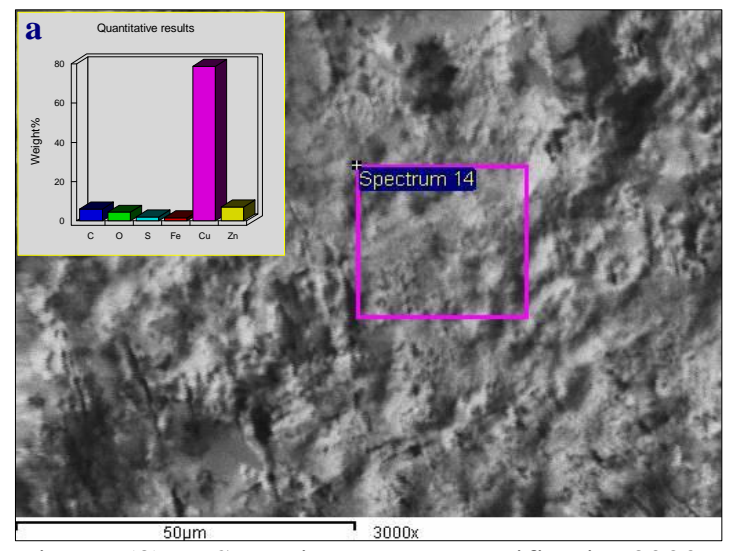

spectrum from the object surface was $50 \mu \mathrm{m}$; whereas EDX analysis of the same location, figs. (3-b) contains the elements of $4.47 \% \mathrm{O}_{2}$ oxygen, $1.98 \% \mathrm{~S}$ sulfur, $1.53 \% \mathrm{Fe}$ iron, $78.92 \% \mathrm{Cu}$ copper and $7.15 \% \mathrm{Zn}$ zinc.

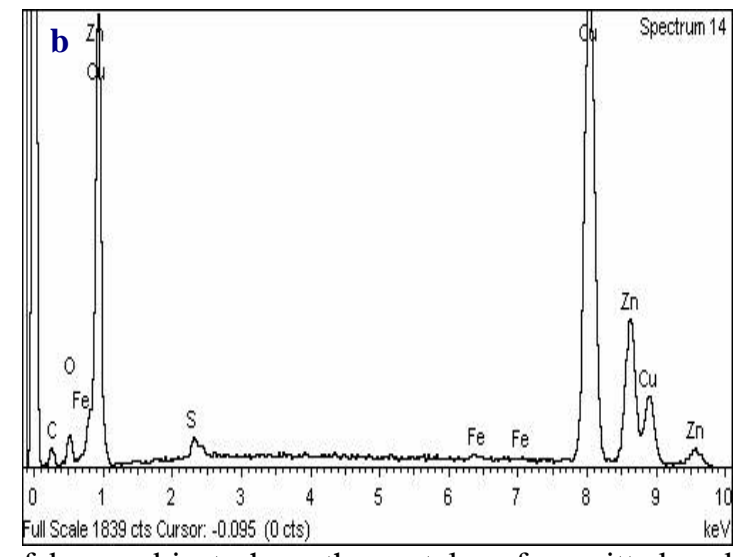

Figure (3) a SEM image at magnification3000x of brass object show the metal surface pitted and etched and SEM-EDX microanalysis of the studies sample, $\underline{\mathbf{b}}$ EDX pattern shows the brass alloy consists of $78.92 \%$ copper, $7.15 \%$ zinc, $1.98 \%$ sulfur and $1.53 \%$ Iron

\subsection{X-Ray diffraction analysis (XRD)}

XRD data, fig. (4) show that, sample consists of cuprite copper oxide $\mathrm{Cu}_{2} \mathrm{O}$ card no. (05-0667); and atacamite $\left(\mathrm{Cu}_{2} \mathrm{Cl}(\mathrm{OH})_{3}\right)$ card No $(02-0145)$ as

$(\mathrm{CuCl})$ copper chloride card No (06$0344)$ and copper iron sulfide $((\mathrm{Cu}, \mathrm{Fe})$ $\left.\mathrm{S}_{2}\right)$ card No (24-0365) as minor minerals. major minerals; in addition to nantokite

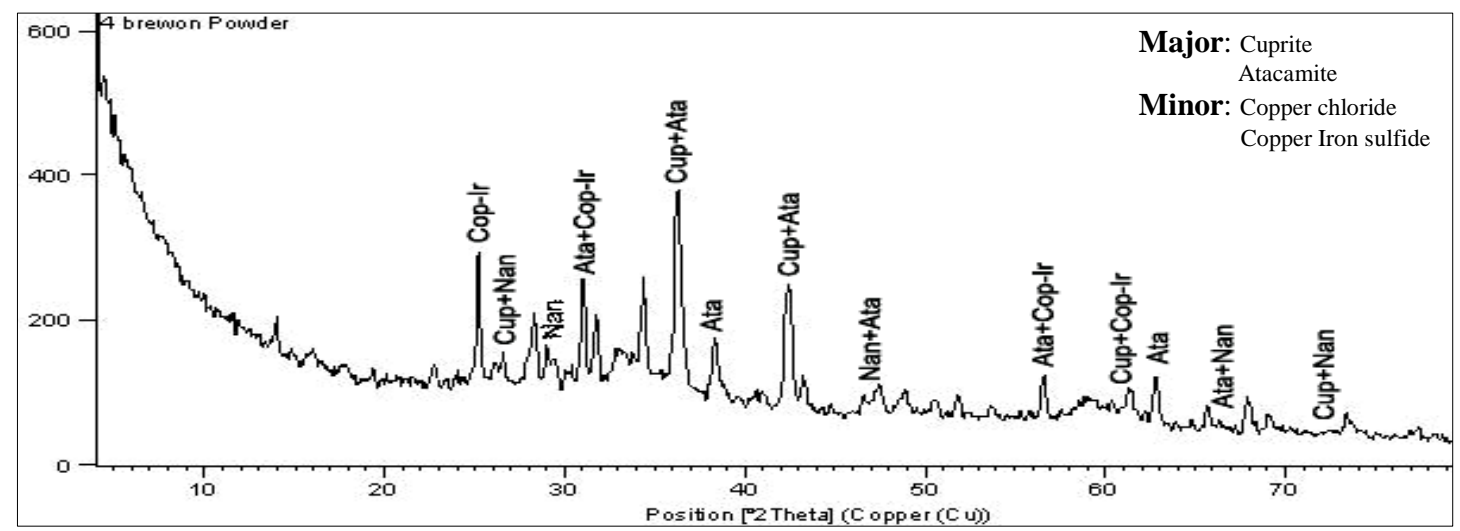

Figure (4) XRD pattern of the studied sample consists of Cuprite, Atacamite as major minerals and Nantokite, copper iron sulfide as minor minerals.

\subsection{Raman spectroscopy}

The author applied Raman spectroscopy for the study of minerals containing copper corrosion layer (patina), different Raman spectra were collected, table (1) \& fig s. $(5,6,7)$; All resulted compounds were identified through comparing their characteristic of vibrational spectra with those in published

databases, fig. (8) [15][16][17] [18]. The mineral detected by Jasco microscope model (FT/IR-6300 type A); which Raman spectra were excited by Nd-YAG laser $1064 \mathrm{~nm}$ was Azurite, Azurite revealed its characteristic bands at 1587 , $1080,858,418$. The minerals detected by Senterra Raman spectrometer which 
Raman spectra were excited by Nd-YAG laser $532 \mathrm{~nm}$ were atacamite and paratacamite, atacamite displays bands at 110, 993, 515, 3337, and 3444, paratacamite displays bands at 360,515 , 930, and 975. Raman spectra exited by $\mathrm{Nd}-\mathrm{YAG}$ laser $785 \mathrm{~nm}$ revealed other minerals, antlerite $\left(\mathrm{Cu}_{3}\left(\mathrm{SO}_{4}\right)(\mathrm{OH})_{4}\right)$ revealed its characteristic bands at 1910 , 1255, 1182, 1143, and 418. The Raman spectra of mineral brochantite $\left(\mathrm{Cu}_{4}\left(\mathrm{SO}_{4}\right)\right.$ $\left.(\mathrm{OH})_{6}\right)$ showed bands at 1107, 1182, 1143,506 , and 418. Posnjakite $\left(\mathrm{Cu}_{4}\right.$ $\left.\left(\mathrm{SO}_{4}\right)(\mathrm{OH}) 6 \mathrm{H}_{2} \mathrm{O}\right)$ displayed bands at $1910,1255,1161,1143,1107,506$, and 418.

Table (1) minerals analyzed using visible excitation

\begin{tabular}{llc}
\hline \multicolumn{1}{c}{ Mineral name \& composition } & \multicolumn{1}{c}{ Band wavenumber/cm } & Type of laser power \\
\hline Azurite $\mathrm{Cu}_{3}\left(\mathrm{CO}_{3}\right)_{2}(\mathrm{OH})_{2}$ & $1587,1080,858,418$. & $1064 \mathrm{~nm}$ \\
Atacamite $\mathrm{Cu}_{2} \mathrm{Cl}(\mathrm{OH})_{3}$ & $110,993,515,3337,3444$ & $532 \mathrm{~nm}$ \\
Paratacamite $\mathrm{Cu}_{2} \mathrm{Cl}(\mathrm{OH})_{3}$ & $360,515,930,975$ & $532 \mathrm{~nm}$ \\
Antlerite $\mathrm{Cu}_{3}\left(\mathrm{SO}_{4}\right)(\mathrm{OH})_{4}$ & $1910,1255,1182,1143,418$ & $785 \mathrm{~nm}$ \\
Brochanthite $\mathrm{Cu}_{4}\left(\mathrm{SO}_{4}\right)(\mathrm{OH})_{6}$ & $1107,1182,1143,506,418$ & $785 \mathrm{~nm}$ \\
Posnjakite $\mathrm{Cu}_{4}\left(\mathrm{SO}_{4}\right)(\mathrm{OH})_{6} \mathrm{H}_{2} \mathrm{O}$ & $1910,1255,1161,1143,1107,506,418$. & $785 \mathrm{~nm}$
\end{tabular}

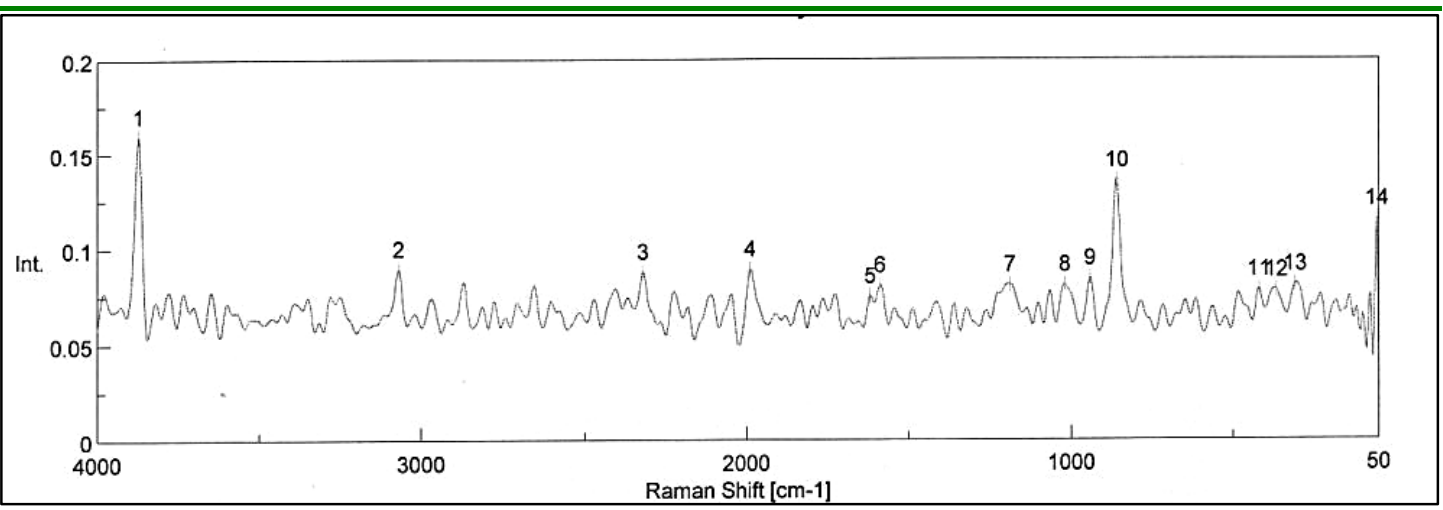

Figure (5) Raman spectrum of the studied sample showed bands of mineral Azurite at 1064nm.
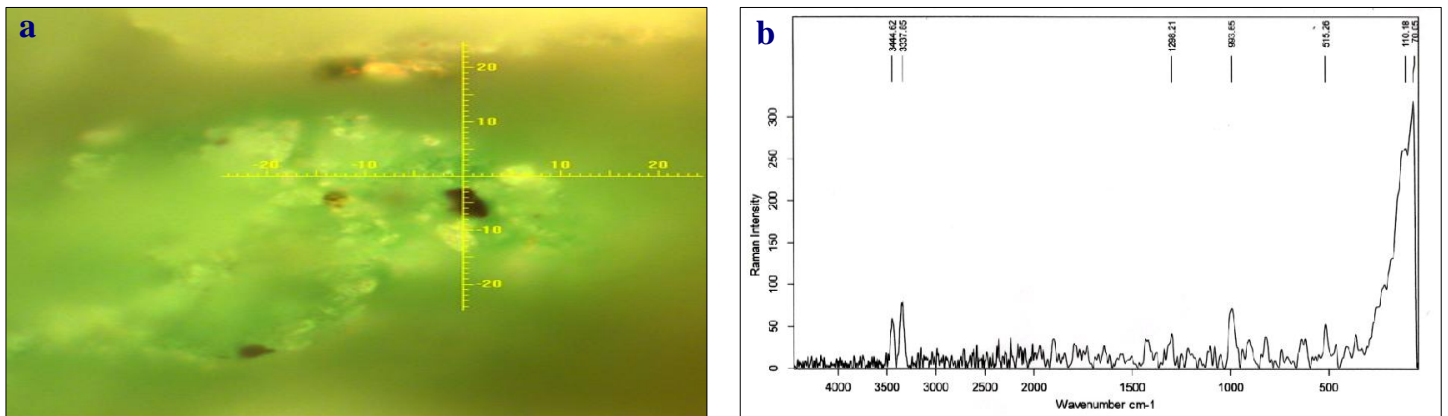

Figure (6) $\underline{\mathbf{a}}$ shows Atacmite \& Paratcmite image, $\underline{\mathbf{b}}$ Raman spectrum of the sample bands of the minerals at $532 \mathrm{~nm}$
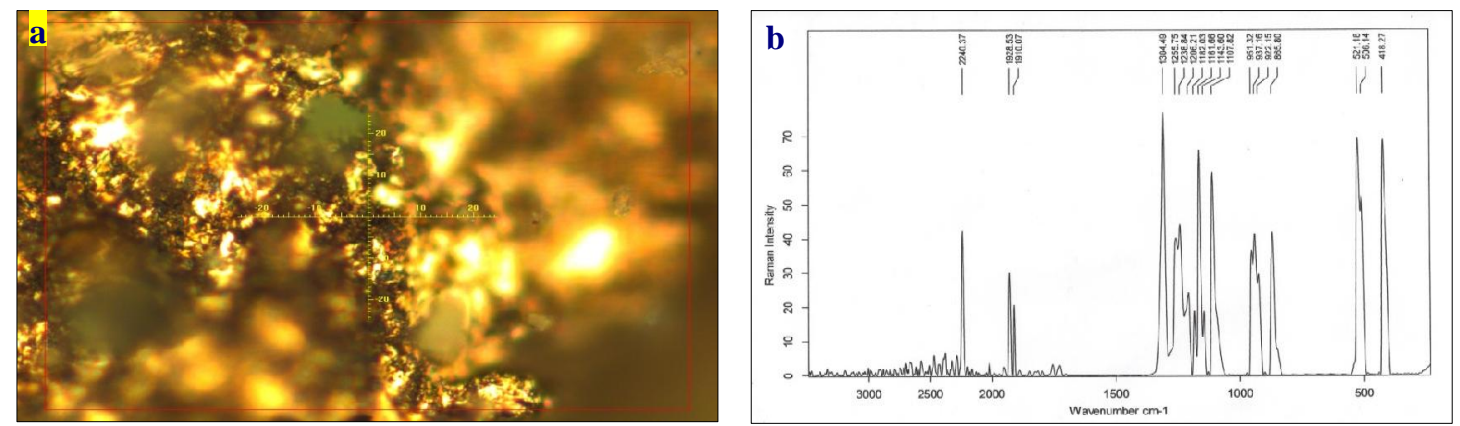

Figure (7) a shows Antlerite, Brochanthite, \& Posnjakite image, b Raman spectrum of the sample showed bands of the minerals at $785 \mathrm{~nm}$. 

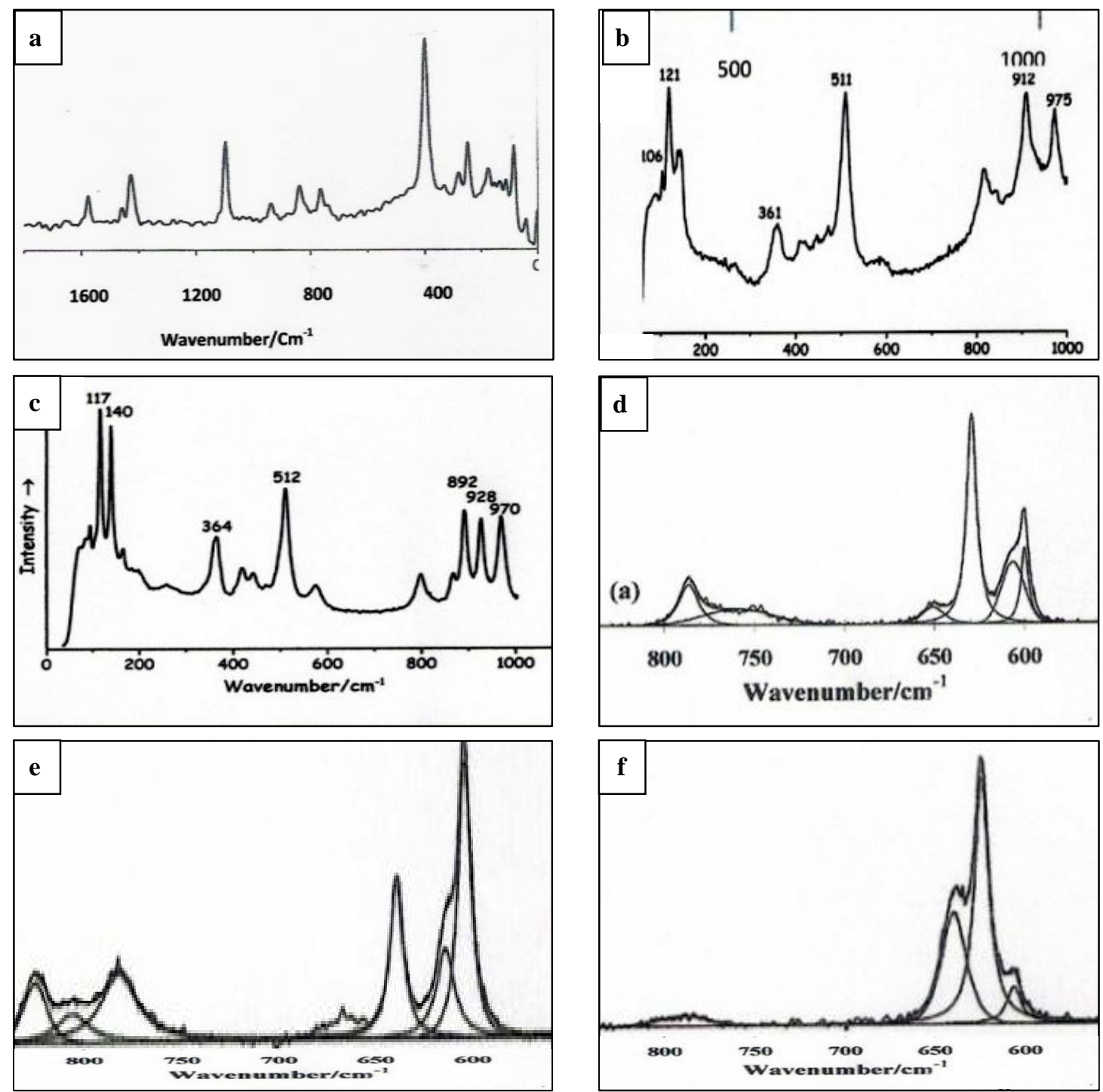

Figure (8) Reference of FTIR spectra of [A] Azurite, [B] Atacmite, [C] Paratcmite, [D] Antlerite, [E] Brochanthite, $[\mathrm{F}]$ Posnjakite.

\section{Treatment}

\subsection{Mechanical cleaning}

A variety of brushes, abrasives and hand tools are applied in mechanical methods of cleaning [19]. Mechanical methods must be preferred whenever possible because they are controllable and do not involve aggressive chemicals. However, removing the corrosion crust piece-by-piece under the microscope is

\subsection{Galvanic cleaning}

In electrochemical corrosion, a galvanic cell is created when two different metals, are coupled by means of an electrical or ion-conducting electrolyte. The result is an electrochemical reaction. In essence, electrochemical corrosion is reserved for those processes where a

very time-and labor-consuming [20]. The uses of chisels are generally the most utilized and effective means of removing encrustation. Chisels can be easily fabricated in the laboratory for specific jobs, and their use is often desirable and quite effective in freeing movable parts on artifacts [21].

current flows between anodic and cathodes areas situated at different parts of a metallic surface or between two different metals [22]. In this process, the artifact is brought into contact with a piece of less noble metal like mild steel; the object is left in the solution $(10 \%$ 
sodium hydroxide as the electrolyte) until the steel is oxidized and the process is repeated until the desirable result is achieved. The treatment completed by immersing an object in a solution of $3 \%$

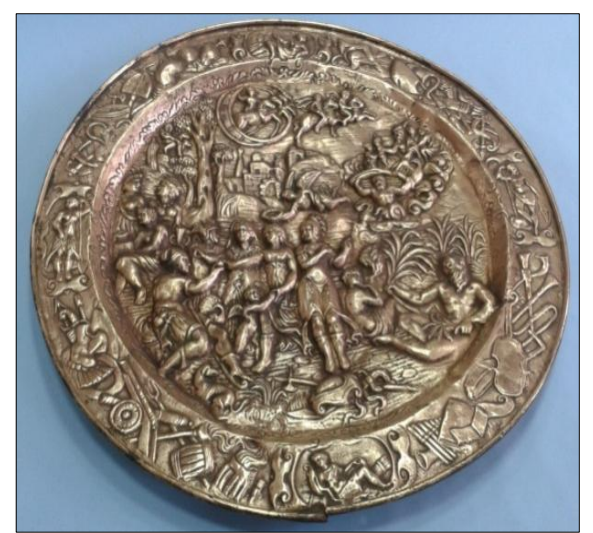

benzotriazole BTA dissolved in ethanol; it should be wiped off with a rag saturated in ethanol to remove excess BTA [23][24][25][26], fig. (9).

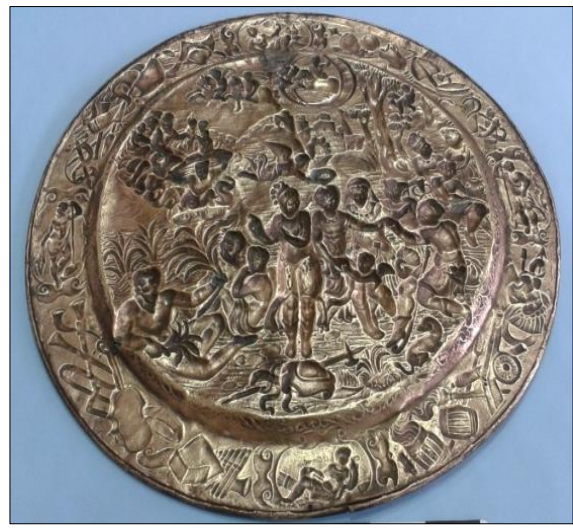

Figure (9) the brass object from the front and behind surface after treatment process.

\section{Discussion}

The investigation of the copper object surface using $\mathrm{OM}$ and SEM microscopy showed the surface appeared heterogeneous, this layer had different features. In some parts it was continuous, most even, and less thick, in other parts the surface covered in holes, pits, cracks, and flakes. The Raman spectroscopy, XRD and EDX analysis of the samples revealed the alloy of the object was brass alloy which consists of copper and zinc; and the corrosion crust had porous structure with chemical elements: $\mathrm{Cu}, \mathrm{Zn}$, $\mathrm{S}, \mathrm{Cl}, \mathrm{O}$, and $\mathrm{Fe}$. The presence of $\mathrm{Cu}$ and $\mathrm{Zn}$ was assumed to be the result of microelements in its basic alloy, $\mathrm{Fe}, \mathrm{Cl}$, $\mathrm{S}$, and $\mathrm{O}$ presented contamination microstructure in the soil [27]. Cuprite is the first product of copper corrosion, forms epitaxial as a product of the direct reaction of copper with dissolved $\mathrm{O}_{2}$ oxygen or with molecules. Cuprite had a high electrical conductivity and permits transport of copper ions through the cuprite layers (the primary patina), allowing the copper ions to dissolve in water and precipitate. Copper ions precipitate as botallackite $\left(\mathrm{Cu}_{2}(\mathrm{OH})_{3} \mathrm{Cl}\right)$ which can convert in minutes or hours to either paratacamite or atacamite $\left(\mathrm{Cu}_{2}\right.$ $(\mathrm{OH})_{3} \mathrm{Cl}$ ) (alternate crystal structures of botallackite) [28]. Then they generalize on large areas, including the mineralization of other cationic and anionic species, and form the secondary patina, a first phase in the formation of the secondary patina is the transformation of cuprite and chalcocite into malachite, azurite, atacamite, paratacamite, antlerite, brocantite and nantochite. In moist atmospheres brochantite will change to posnjakite or langite depending on the $\mathrm{pH}$ and sulphate concentrations. However langite is meta- stable with respect to brochantite and so the latter will be the phase observed in the corrosion products of copper and brass [29]. The secondary patina, by developing in contact with some micro-structure from the site, embeds them into the surface of the object (by processes of mineralization), forming the tertiary, or the contamination patina [9]. The tertiary patina is shaped as monolith bulks, with or without metallic core, with embedded micro-structure of animal fibers, insects etc.

\section{Conclusion}

In the presence of pollutants, copper alloys develop a patina that acquires different colors in time: light-green, grey-green, brown-green. The color of the patina formed on copper alloys is set by the corrosion products. The corrosion crust formed on brass artifacts are characterized by the presence primary and secondary chemical 
compounds deposits and micro-structure from the soil. We observed the unevenness of the corrosion crust. The examination under optical microscope and SEM conditions allowed us to identify the nature of the alloy, characterized by the presence of pits, holes, and crocks. The EDX, XRD and Raman spectroscopy results identified the first and second layers were composed of different corrosion compounds, such as oxides, carbonate, sulphate, and chlorides of copper, while the third layer was composed of corrosion products and soil compounds. This study provides useful information for the conservation and protection of the brass object. Treatment process of brass object was carried out by using mechanical cleaning and galvanic method, the galvanic method with sodium hydroxide is a quite effective and not harmful method for reduction of the corrosion layer. The conservation project was successful.

\section{References}

[1] Loanid, A. \& Ruse, D., (2011). Surface investigation of some medieval silver coins cleaned in high-frequency, J. of Cultural Heritage, Vol. 12, pp. 220- 226.

[2] Mircea, O., Sandu, I., Vasilach, V. \& Sandu, I.G, (2012). A study on the deterioration and degradation of metallic archaeological artifacts, IJCS, Vol. 3 (3), pp.179-188.

[3] Herrera, L., (2009). Surface analysis and materials characterization for the study of bio deterioration and weathering effects on cultural property, Int. Bio Deterioration \& Bio Degradation, Vol. 63, pp. 813-822.

[4] Calligaro, T., Darn, J. \& Salomon, J., (2004). Ion beam analysis, in: Janssens, K. \& Van Grieken, R. (Eds.) Non-destructive Microanalysis of Cultural Heritage Materials, Ch. 5, Elsevier, Amsterdam, pp. 227-276.

[5] Sandu, I., Ursulescu, N., Sandu, I.G., Bounegru, O., Sandu, I.C.A. \& Alexandru, A., (2008). Stratification effect of corrosion and contamination products on Byzantine bronze artifacts, Corrosion Engineering Science and Technology, Vol. 43 (3), pp. 256-266.

[6] Sandu, I.G., Stoleriu, S., Sandu, I., Brebu, M. \& Sandu, A.V., (2005). Authentication of ancient bronze coins by the study of the archaeological patina. I. Composition and structure, Revista de Chimie (Bucharest), Vol. 56 (10), pp. 981-994.
[7] Trentelman, K., Stodulski, L., Scott, D., Back, M., Stock, S., Strahan, D., Drews, A., O'Neill, A., Weber, W., Chen, A. \& Garrett, S., (2002). The Characterization of a New Pale Blue Corrosion Product Found on Copper Alloy Artifacts, Studies in Conservation, Vol. 47 (4), pp. 217-227.

[8] Lucey, V., (1972). Development leading to the present understanding of the mechanism of pitting corrosion of copper, British Corrosion Journal, Vol. 7 (1), pp. 36-41.

[9] Robbiola, L., Blengino, J. \& Fiaud, C., (1998). Morphology and mechanisms formation of natural patinas on archaeological $\mathrm{Cu}-\mathrm{Sn}$ alloys, Corrosion Science, Vol. 40 (12), pp. 2083-2111.

[10] Mathis, F., Delange, E., Robcis, D. \& Aucouturier, M., (2009). HMTYKM (black copper) and the Egyptian bronzes' collection of the museum du Louvre, J. of Cultural Heritage, Vol. 10 (1), pp. 63- 72.

[11] Serra, A., Manno, D., Filippo, E., Vitale, R., Sarcinelli, G., Calcagnile, L., Quarta, G., Giovannelli, G., Bozzini, B. \& Siciliano, A., (2010). Unusual coin from the parabita hoard: combined use of surface and micro-analytical techniques for its characterization, $J$. of Cultural Heritage, Vol. 11 (2), pp.: 233-238.

[12] White, S., (2009). Laser Raman spectroscopy as a technique for identification of seafloor hydrothermal and cold seep 
minerals, Chemical Geology, Vol. 259, pp.240-252

[13] Martens, W., Frost, R., Kloprogge, J. \& Williams, P.A., (2003). Raman spectroscopic studies of the basic copper sulphates-implications for copper corrosion and "bronze disease", J. of Raman spectroscopy, Vol.34 (2), pp.:145- 151

[14] McNeil, M. \& Little, B., (1992). Corrosion mechanisms for copper and silver objects in near-surface environments, $J$. of the American institute for conservation, vol.31, pp.:355-366.

[15] Frost, R., Hales, M. \& Reddy, B., (2007). Aurichalcite-An SEM and Raman spectroscopic study, Polyhedron, Vol. 26 (13), pp. 3291- 3300.

[16] Bouchard, M., Smith, D., (2003). Catalogue of 45 reference Raman spectra of minerals concerning research in art history or archaeology, especially on corroded metals and colored glass, Spectrochimica Acta Part A: Molecular and Biomolecular Spectroscopy, Vol. 59 (10), pp.: 2247-2266.

[17] Burgio, L. \& Clark, R., (2001). Library of FT-Raman spectra of pigments, minerals, pigment media and varnishes, and supplement to existing library of Raman spectra of pigments with visible excitation, Spectrochimica Acta Part A: Molecular and Biomolecular Spectroscopy, Vol.57 (7), pp.1491-1521.

[18] Król, A., Hoffmann, A. \& Gutowski, J., (1988). Raman studies of hexagonal ZnS: Al, Physical Review $B$, Vol. 38 (15), pp. 10946-10948.

[19] Viljus, A. \& Viljus, M., (2013). The conservation of early postmedieval period coins found in Estonia, Journal of conservation \& museum studies, Vol. 10 (2), pp. 30- 44.

[20] Cronyn, J.M., (1990).The elements of archaeological conservation, Routledge, London.
[21] Ghoneim, M., Megahid, M., (2009). Treatment and conservation of a group of Raman coin discovered in Tell Baste, Egypt, in: Ferrari, A (Ed.) Proceeding of $4^{\text {th }}$ Int. Cong. on science and technology for the safeguard of cultural heritage in the Mediterranean Basin, Vol. II. Cairo, Egypt, pp. 143-153.

[22] Hamilton, D., (1999). Methods of conservation archaeological material from underwater sites, Texas A\&M Univ., USA, pp. 74- 76.

[23] Seas, C., (1978). Benzotriazole: A review for conservators. Studies in Conservation, Vol. 23, pp. 76-85.

[24] Merk, L., (1981). The effectiveness of benzotriazole in the inhibition of the corrosive behavior of stripping reagents on bronzes, Studies in Conservation, Vol. 26, pp.73-76.

[25] Mircea, O., Sandu, I., Vasilach, V., Sandu, A, (2013). Application microscopy and energy-dispersive $\mathrm{x}$ - ray spectroscopy in the study of a pendant from the $\mathrm{II}^{\mathrm{ND}}$-III ${ }^{\mathrm{RD}}$ century A.C., IJCS, Vol. 4, pp. 701- 709.

[26] Thicket, D., Enderly, C., (1997). The cleaning of coin Hoard: The benefits of a collaborative approach, in: Bradley, S. (Ed.). The interface between science and conservation, British Museum, London, No.16, pp. 183- 192.

[27] McNeill, M., Little, B.J., (1992). Corrosion mechanism for copper and silver objects in near-surface environments, JAIC, Vol. 31 (3), pp. 355-366.

[28] Scott, D., (1994). An examination of the patina and corrosion morphology of some roman bronzes, JAIC, Vol. 33 (1), pp. 1-23.

[29] Franke, W., Mircea, M., (2005). Report on the blue patina of bronze statue at Delphi, JAIC, Vol. 44 (2), pp. 103-116. 